Journal of Mathematics and Statistics: 4(3): 156-160, 2008

ISSN: $1549-3644$

(C) 2008 Science Publications

\title{
On Cesáro means for Fox-Wright functions
}

\author{
Maslina Darus and Rabha W. Ibrahim \\ School of Mathematical Sciences, Faculty of Science and Technology \\ University Kebangsaan Malaysia, Bangi 43600 Selangor D. Ehsan, Malaysia
}

\begin{abstract}
The polynomial approximants which retain the zero free property of a given analytic function involving fox-wright function in the unit disk $U:=\{z:|z|<1\}$ is found. The convolution methods of a geometric function that the Cesáro means of order $\mu$ retains the zero free property of the derivatives of bounded convex functions in the unit disk are used. Other properties are also established.
\end{abstract}

Key words: Fox-wright function, cesáro sum, convolution

\section{INTRODUCTION}

In the theory of approximation, the important problem is to find a suitable finite (polynomial) approximation for the outer infinite series $f$ so that the approximant reduces the zero-free property of $\mathrm{f}$ Recall that an outer function (zero-free) is a function $f \varepsilon \mathrm{H}$ of the form:

$$
f(z)=e^{i \gamma} e^{1 / 2 \pi} f_{-\pi}^{\pi} \frac{1+e^{i t} z}{1-e^{i t} z} \log \psi(t) d t
$$

where, $\psi(\mathrm{t}) \geq 0, \log \psi(\mathrm{t})$ is in $\mathrm{L}^{1}$ and $\Psi(\mathrm{t})$ is in $\mathrm{L}^{\mathrm{p}[3]}$. Outer function plays an important role in $\mathrm{H}^{\mathrm{p}}$ theory, arises in characteristic equation which determines the stability of certain nonlinear systems of differential equations ${ }^{[2]}$. We observed that for outer functions, the standard Taylor approximants do not, in general, retain the zero-free property of $\mathrm{f}$ It was shown $\mathrm{in}^{[1]}$ that the Taylor approximating polynomials to outer functions can vanish in the unit disk. By using convolution methods, the classical Cesáro means retain the zero-free property of the derivatives of bounded convex functions in the unit disk. The classical Cesáro means play an important role in geometric function theory ${ }^{[5-7]}$. In this study, we obtain new Cesáro approximants for outer functions. Indeed, fox-wright function is involved and stated as follows:

For complex parameters:

$$
\alpha 1, \ldots, \alpha_{\mathrm{q}}\left(\frac{\alpha_{j}}{A_{j}} \neq 0,-1,-2, \ldots ; j=1, \ldots, q\right)
$$

And

$$
\beta_{1}, \ldots, \beta_{p}\left(\frac{\beta_{j}}{B_{j}} \neq 0,-1,-2, \ldots ; j=1, \ldots, p\right),
$$

the fox-wright generalization ${ }_{\mathrm{q}} \psi_{\mathrm{p}}[\mathrm{z}]$ of the hypergeometric ${ }_{\mathrm{q}} \mathrm{F}_{\mathrm{q}}$ function by ${ }^{[4,10,11]}$ :

$$
\begin{aligned}
{ }_{\mathrm{q}} \psi_{\mathrm{p}}\left[\begin{array}{c}
\left(\alpha_{1}, \mathrm{~A}_{1}\right), \ldots,\left(\alpha_{\mathrm{q}}, \mathrm{A}_{\mathrm{q}}\right) ; \\
\left(\beta_{1}, \mathrm{~B}_{1}\right), \ldots,\left(\beta_{\mathrm{p}}, \mathrm{B}_{\mathrm{p}}\right) ;^{\mathrm{z}}
\end{array}\right] & ={ }_{\mathrm{q}} \psi_{\mathrm{p}}\left[\left(\alpha_{\mathrm{j}}, \mathrm{A}_{\mathrm{j}}\right)_{1, \mathrm{q}} ;\left(\beta_{\mathrm{j}} \mathrm{B}_{\mathrm{j}}\right)_{1, \mathrm{p}} ; \mathrm{z}\right] \\
& :=\sum_{\mathrm{n}=0}^{\infty} \frac{\Gamma\left(\alpha_{1}+\mathrm{nA}_{1}\right) \ldots \Gamma\left(\alpha_{\mathrm{q}}+\mathrm{nA}_{\mathrm{q}}\right) \mathrm{z}^{\mathrm{n}}}{\Gamma\left(\beta_{1}+\mathrm{nB}_{1}\right) \ldots \Gamma\left(\beta_{\mathrm{p}}+\mathrm{nB}_{\mathrm{p}}\right) \mathrm{n} !} \\
& =\sum_{\mathrm{n}=0}^{\infty} \frac{\prod_{\mathrm{j}=1}^{\mathrm{q}} \Gamma\left(\alpha_{\mathrm{j}}+\mathrm{nA}_{\mathrm{j}}\right) \mathrm{z}^{\mathrm{n}}}{\Pi_{\mathrm{j}=1}^{\mathrm{p}} \Gamma\left(\beta_{\mathrm{j}}+\mathrm{nB}_{\mathrm{j}}\right) \mathrm{n} !}
\end{aligned}
$$

where, $A_{j}>0$ for all $j=1, \ldots, q, B>0$ for all $j=1, . ., p$ and nship $1+\sum_{j=1}^{p} B_{j}-\sum_{j=1}^{q} A_{j} \geq 0$ for suitable values $|z|$ For special case, when $A_{j}=1$ for all $j=1$ and $B_{j}=1$ for all $\mathrm{j}=1, \ldots, \mathrm{p}$ we have the following relationship:

$$
\begin{gathered}
{ }_{\mathrm{q}} \mathrm{F}_{\mathrm{p}}\left(\alpha_{1}, \ldots, \alpha_{\mathrm{q}} ; \beta_{1}, \ldots, \beta_{\mathrm{p}} ; \mathrm{z}\right)=\Omega_{\mathrm{q}} \Psi_{\mathrm{p}}\left[\left(\alpha_{\mathrm{j}}, 1\right)_{1, \mathrm{q}} ;\left(\beta_{\mathrm{j}}, 1\right)_{1, \mathrm{p}} ; \mathrm{z}\right] \\
\mathrm{q} \leq \mathrm{p}+1 ; \mathrm{q}, \mathrm{p} \in \mathrm{N}_{0}=\mathrm{N} \bigcup\{0\}, \mathrm{z} \in \mathrm{U}
\end{gathered}
$$

Where:

$$
\Omega:=\frac{\Gamma\left(\beta_{1}\right) \ldots \Gamma\left(\beta_{\mathrm{p}}\right)}{\Gamma\left(\alpha_{1}\right) \ldots \Gamma\left(\alpha_{\mathrm{q}}\right)}
$$

Let $\mathrm{A}$ be the class of Fox-Wright functions in the unit disk $\mathrm{U}:=\{\mathrm{z}:|\mathrm{z}|<1\}$ take the form:

Corresponding Author: Maslina Darus, School of Mathematical Sciences, Faculty of Science and Technology, Universiti Kebangsaan Malaysia, Bangi 43600 Selangor D. Ehsan, Malaysia 


$$
\begin{aligned}
& \varphi(z):=z_{q} \Psi_{p}\left[\left(\alpha_{j}, A_{j}\right)_{1, q} ;\left(\beta_{j}, B_{j}\right)_{1, p} ; z\right] \\
& =\sum_{n=0}^{\infty} \frac{\prod_{j=1}^{q} \Gamma\left(\alpha_{j}+n A_{j}\right) z^{n+1}}{\prod_{j=1}^{p} \Gamma\left(\beta_{j}+n B_{j}\right) n !}, z \in U
\end{aligned}
$$

With:

$$
0<\prod_{j=1}^{q} \Gamma\left(\alpha_{j}+n A_{j}\right) \leq \prod_{j=1}^{p} \Gamma\left(\beta_{j}+n_{j}\right)
$$

\section{RESULTS AND DISCUSSION}

This class of function is a generalization to the one studied by ${ }^{[5]}$. The author observed the following results:

Lemma 1: Let $0<\alpha \leq \beta$ If $\beta \geq 2$ or $\alpha+\beta \geq 3$ then the function of the form $f(z)=\sum_{n=0}^{\infty} \frac{(\alpha) n}{(\beta) n} z^{n+1}, z \in U$ is convex. by:

Note that $(\mathrm{x})$ is the Pochhammer symbol defined

$$
(\mathrm{x})_{\mathrm{n}}=\frac{\Gamma(\mathrm{x}+\mathrm{n})}{\Gamma(\mathrm{x})}=\left\{\begin{array}{l}
1, \mathrm{n}=0 \\
\mathrm{x}(\mathrm{x}+1) \ldots(\mathrm{x}+\mathrm{n}-1), \mathrm{n}=\{1,2, \ldots\}
\end{array}\right\}
$$

Lemma 2: Assume that $a_{1}=1$ and $a_{n} \geq 0$ for $n \geq 0$ such that $\left\{a_{n}\right\}$ is a convex decreasing sequence i.e.:

$$
a_{n}-2 a_{n+1}+a_{n+2} \geq 0 \text { and } a_{n+1}-a_{n+2} \geq 0
$$

Then

$$
\mathfrak{R}\left\{\sum_{\mathrm{n}=1}^{\infty} \mathrm{a}_{\mathrm{n}} \mathrm{z}^{\mathrm{n}-1}\right\}>\frac{1}{2}, \mathrm{z} \in \mathrm{U}
$$

We apply Lemma 1.2, to find the next result which is a generalization to ${ }^{[\text {Lemma } 5 ; 8] \text {. }}$

Lemma 3: Let (2) holds. Then:

$$
\Re\left\{\frac{\varphi(\mathrm{z})}{\mathrm{z}}\right\}>\frac{1}{2} \text { for all } \mathrm{z} \in \mathrm{U}
$$

Proof: From the definition of the function $\varphi(z)$ we have:

$$
\frac{\varphi(\mathrm{z})}{\mathrm{z}}=\frac{\Gamma\left(\alpha_{1}\right) \ldots \Gamma\left(\alpha_{\mathrm{q}}\right)}{\Gamma\left(\beta_{1}\right) \ldots \Gamma\left(\beta_{\mathrm{p}}\right)}+\sum_{\mathrm{n}=2}^{\infty} \mathrm{B}_{\mathrm{n}} \mathrm{z}^{\mathrm{n}-1}
$$

Where:

$$
\mathrm{B}_{\mathrm{n}}:=\frac{\Gamma\left(\alpha_{1}+(\mathrm{n}-1) \mathrm{A}_{1}\right) \ldots \Gamma\left(\alpha_{\mathrm{q}}+(\mathrm{n}-1) \mathrm{A}_{\mathrm{q}}\right) 1}{\Gamma\left(\beta_{1}+(\mathrm{n}-1) \mathrm{B}_{1}\right) \ldots \Gamma\left(\beta_{\mathrm{p}}+(\mathrm{n}-1) \mathrm{B}_{\mathrm{p}}\right) \Gamma(\mathrm{n})}
$$

for $n \geq 2$. From (2), we have $B_{n}>0$ for all $n \in N$ Now by using Gauss's multiplication theorem for the Gamma function, it follows that:

$$
\Gamma[\mathrm{k}(\mathrm{n}+\gamma)]=\Gamma(\mathrm{k} \gamma)\left(\mathrm{k}^{\mathrm{k}}\right)^{\mathrm{n}}(\gamma)_{\mathrm{n}}\left(\gamma+\frac{1}{\mathrm{k}}\right)_{\mathrm{n} . . .}\left(\gamma+\frac{\mathrm{k}-1}{\mathrm{k}}\right)_{\mathrm{n}}
$$

for positive integer $\mathrm{k}$ and non-negative integer $\mathrm{n}$ Thus since we obtain ${ }^{[9]}$ :

$$
\Gamma\left(\alpha+\mathrm{A}_{\mathrm{n}}\right)=\Gamma(\alpha)\left(\frac{\alpha}{\mathrm{A}}\right)_{\mathrm{n}}\left(\frac{\alpha+1}{\mathrm{~A}}\right)_{\mathrm{n}} \ldots\left(\frac{\alpha+\mathrm{A}-1}{\mathrm{~A}}\right)_{\mathrm{n}}\left(\mathrm{A}^{\mathrm{A}}\right)^{\mathrm{n}}
$$
find:

Also, by using the fact that $(\mathrm{x})_{\mathrm{n}}=(\mathrm{x})_{\mathrm{n}-1}(\mathrm{x}+\mathrm{n}-1)$, we

$$
B_{n}=\frac{\prod_{j=1}^{q} \Gamma\left(\alpha_{j}\right)\left(\frac{\alpha_{j}}{A_{j}}\right)_{n-1}\left(\frac{\alpha_{j}+1}{A_{j}}\right)_{n-1} \ldots\left(\frac{\alpha_{j}+A_{j}-1}{A_{j}}\right)_{n}\left(A_{j}^{A_{j}}\right)^{n-1}}{\prod_{j=1}^{p} \Gamma\left(\beta_{j}\right)\left(\frac{\beta_{j}}{B_{j}}\right)_{n-1}\left(\frac{\beta_{j}+1}{B_{j}}\right)_{n-1} \ldots\left(\frac{\beta_{j}+B_{j}-1}{B_{j}}\right)_{n-1}\left(B_{j}{ }^{B j}\right)^{n-1}}
$$

Then we obtain $B_{n} \geq 0$. Moreover, we have $\mathrm{B}_{\mathrm{n}+1}$ and $\mathrm{B}_{\mathrm{n}+2}$ in terms of $\mathrm{B}_{\mathrm{n}}$ :

$$
\begin{aligned}
B_{n+1}= & \frac{\Gamma\left(\alpha_{1}+n A_{1}\right) \ldots \Gamma\left(\alpha_{q}+n A_{q}\right) 1}{\Gamma\left(\beta_{1}+n B_{1}\right) \ldots \Gamma\left(\beta_{p}+n B_{p}\right) n \Gamma(n)} \\
= & \frac{\prod_{j=1}^{q} \Gamma\left(\alpha_{j}\right)\left(\frac{\alpha_{j}}{A_{j}}\right) n\left(\frac{\alpha_{j}+1}{A_{j}}\right) n \ldots\left(\frac{\alpha_{j}+A_{j}-1}{A_{j}}\right) n\left(A_{j}^{A j}\right)^{n}}{\prod_{j=1}^{p} \Gamma\left(\beta_{j}\right)\left(\frac{\beta_{j}}{B_{j}}\right) n\left(\frac{\beta_{j}+1}{B_{j}}\right) n \ldots\left(\frac{\beta_{j}+B_{j}-1}{B_{j}}\right) n\left(B_{j}^{B j}\right)^{n}} \frac{1}{n \Gamma(n)} \\
= & \frac{\prod_{j=1}^{q}\left(\frac{\alpha_{j}}{A_{j}}+n-1\right)\left(\frac{\alpha_{j}+1}{A_{j}}+n-1\right) \ldots\left(\frac{\alpha_{j}+A_{j}-1}{A_{j}}+n-1\right)\left(A_{j}^{A_{j}}\right)}{\prod_{j=1}^{p}\left(\frac{\beta_{j}}{B_{j}}+n-1\right)\left(\frac{\beta_{j}+1}{B_{j}}+n-1\right) \ldots\left(\frac{\beta_{j}+B_{j}-1}{B_{j}}+n-1\right)\left(B_{j}^{B_{j}}\right)} \\
& \frac{B_{n}}{n \Gamma(n)}
\end{aligned}
$$

and

$\mathrm{B}_{\mathrm{n}+2}=\frac{\Gamma\left(\alpha_{1}+(\mathrm{n}+1) \mathrm{A}_{1}\right) \ldots \Gamma\left(\alpha_{\mathrm{q}}+(\mathrm{n}+1) \mathrm{A}_{\mathrm{q}}\right)}{\Gamma\left(\beta_{1}+(\mathrm{n}+1) \mathrm{B}_{1}\right) \ldots \Gamma\left(\beta_{\mathrm{p}}+(\mathrm{n}+1) \mathrm{B}_{\mathrm{p}}\right)} \frac{1}{\mathrm{n}(\mathrm{n}+1) \Gamma(\mathrm{n})}$

$$
=\frac{\prod_{j=1}^{q}\left(\frac{\alpha_{j}}{A_{j}}+n-1\right)\left(\frac{\alpha_{j}}{A_{j}}+n\right)\left(\frac{\alpha_{j}+1}{A_{j}}+n-1\right)\left(\frac{\alpha_{j}+1}{A_{j}}+n\right)}{\prod_{j=1}^{p}\left(\frac{\beta_{j}}{B_{j}}+n-1\right)\left(\frac{\beta_{j}}{B_{j}}+n\right)\left(\frac{\beta_{j}+1}{B_{j}}+n-1\right)\left(\frac{\beta_{j}+1}{B_{j}}+n\right)} \ldots
$$

$$
\frac{\left(\frac{\alpha_{j}+A_{j}-1}{A_{j}}+n-1\right)\left(\frac{\alpha_{j}+A_{j}-1}{A_{j}}+n\right)\left(A_{j}^{A_{j}}\right)}{\left(\frac{\beta_{j}+B_{j}-1}{B_{j}}+n-1\right)\left(\frac{\beta_{j}+B_{j}-1}{B_{j}}+n\right)\left(B_{j}^{B_{j}}\right)} \frac{B_{n}}{n(n+1) \Gamma(n)}
$$

Thus from the assumption it follows that: 


$$
\left(1-\frac{\Pi_{j=1}^{q}\left(\frac{\alpha_{j}}{A_{j}}+n\right)\left(\frac{\alpha_{j}+1}{A_{j}}+n\right)\left(\frac{\alpha_{j}+A_{j}-1}{A_{j}}+n\right)\left(A_{j}^{A j}\right) B_{n}}{\Pi_{j=1}^{p}\left(\frac{\beta_{j}}{B_{j}}+n\right)\left(\frac{\beta_{j}+1}{B_{j}}+n\right)\left(\frac{\beta_{j}+B_{j}-1}{B_{j}}+n\right)\left(B_{j}^{B j}\right) n(n+1) \Gamma(n)}\right)
$$$$
\geq 0, \forall \mathrm{n} \in \dot{\mathrm{U}}
$$

In the same way and by using (3) and (4), we can show that:

$$
\mathrm{B}_{\mathrm{n}}-2 \mathrm{~B}_{\mathrm{n}+1}+\mathrm{B}_{\mathrm{n}+2} \geq 0, \forall \mathrm{n} \in \grave{\mathrm{u}}
$$

Thus we find the sequence $\left\{\mathrm{B}_{\mathrm{n}}\right\}$ is convex decreasing and in virtue of lemma 2, we obtain that:

$$
\mathfrak{R}\left\{\frac{\Gamma\left(\alpha_{1}\right) \ldots \Gamma\left(\alpha_{\mathrm{q}}\right)}{\Gamma\left(\beta_{1}\right) \ldots \Gamma\left(\beta_{\mathrm{p}}\right)}+\sum_{\mathrm{n}=2}^{\infty} \mathrm{B}_{\mathrm{n}} \mathrm{z}^{\mathrm{n}-1}\right\}=\mathfrak{R}\left\{\frac{\varphi(\mathrm{z})}{\mathrm{z}}\right\}>\frac{1}{2}
$$

The proof is complete:

We define $\mathrm{S}^{*}, \mathrm{C}, \mathrm{QS}^{*}$ and $\mathrm{QC}$ the subclasses of A consisting of functions which are, respectively, starlike in $\mathrm{U}$, convex in $\mathrm{U}$, close-to-convex and quasi-convex in $\mathrm{U}$. Thus by definition, we have:

$$
\begin{gathered}
\mathrm{S}^{*}:=\left\{\varphi \in \mathrm{A}: \mathfrak{R}\left(\frac{\left(\mathrm{z} \varphi^{\prime}(\mathrm{z})\right)}{\varphi(\mathrm{z})}\right)>0, \mathrm{z} \in \mathrm{U}\right\}, \\
\mathrm{C}:=\left\{\varphi \in \mathrm{A}: \mathfrak{R}\left(1+\frac{\left(\mathrm{z} \varphi^{\prime \prime}(\mathrm{z})\right)}{\varphi^{\prime}(\mathrm{z})}\right)>0, \mathrm{z} \in \mathrm{U}\right\}, \\
\mathrm{QS}^{*}:=\left\{\varphi \in \mathrm{A}: \exists \mathrm{g} \in \mathrm{S}^{*} \text { s.t. } \mathfrak{R}\left(\frac{\left(\mathrm{z} \varphi^{\prime}(\mathrm{z})\right)}{\mathrm{g}(\mathrm{z})}\right)>0, \mathrm{z} \in \mathrm{U}\right\}
\end{gathered}
$$

And

$$
\mathrm{QC}:=\left\{\varphi \in \mathrm{A}: \exists \mathrm{g} \in \mathrm{Cs.t.} \Re\left(\frac{\left(\mathrm{z} \varphi^{\prime}(\mathrm{z})\right)^{\prime}}{\mathrm{g}^{\prime}(\mathrm{z})}\right)>0, \mathrm{z} \in \mathrm{U}\right\}
$$
that:

It is easily observed from the above definitions

$$
\varphi(z) \in C \Leftrightarrow z \varphi^{\prime}(z) \in S^{*}
$$

And

$$
\varphi(\mathrm{z}) \in \mathrm{QC} \Leftrightarrow \mathrm{z} \varphi^{\prime}(\mathrm{z}) \in \mathrm{QS} *
$$

Note that $\varphi \in Q^{*}$ if and only if there exists a function $g \in \mathrm{S}^{*}$ such that:

$$
\mathrm{z} \varphi^{\prime}(\mathrm{z})=\mathrm{g}(\mathrm{z}) \mathrm{p}(\mathrm{z})
$$

where, $p(z) \in P$ the class of all analytic functions of the form:

$$
p(z)=1+P_{1}+z+p_{2} z^{2}+\ldots, \text { s.t.p }(0)=1
$$

Given two functions:

$$
f, g \in A, f(z)=z+\sum_{n=2}^{\infty} a_{n} z^{n}
$$

and

$$
g(z)=z+\sum_{n=2}^{\infty} b_{n} z^{n}
$$

their convolution or Hadamard product $\mathrm{f}(\mathrm{z})^{*} \mathrm{~g}(\mathrm{z})$ is defined by:

$$
f(z) * g(z)=z+\sum_{n=2}^{\infty} a_{n} b_{n} z^{n}, z \in U
$$

We can verify the following result for $f \in A$ and takes the form (1).

\section{Lemma $4^{[5]}$ :}

- If $\varphi \in \mathrm{C}$ and $g \in \mathrm{S}^{*}$ then $\varphi^{*} \mathrm{~g} \in \mathrm{S}^{*}$

- If $\varphi \in C$ and $g \in S^{*}, p \in P$ with $p(0)=1$ then $\varphi^{*} \mathrm{gp}=\left(\varphi^{*} \mathrm{~g}\right) \mathrm{p}_{1}$ where $\mathrm{p}_{1}(\mathrm{U}) \subset$ close convex hull of $p(U)$

\section{CONCLUSION}

Cesáro approximants for outer functions: The Cesáro sums of order $\mu$ where $\mu \in \mathrm{ù} \cup\{0\}$ of series of the form (1) can defined as:

$$
\sigma_{k}^{\mu}(z, \varphi)=\sigma_{k}^{\mu} * \varphi(z)=\sum_{n=0}^{\infty} \frac{\left(\begin{array}{l}
k-n+\mu \\
k-n
\end{array}\right)}{\left(\begin{array}{l}
k+\mu \\
k
\end{array}\right)} \frac{\prod_{j=1}^{q} \Gamma\left(\alpha_{j}+n A_{j}\right) z^{n+1}}{\prod_{j=1}^{p} \Gamma\left(\beta_{j}+n B_{j}\right) n !}
$$

where, $\left(\begin{array}{l}\mathrm{a} \\ \mathrm{b}\end{array}\right)=\frac{\mathrm{a} !}{\mathrm{b} !(\mathrm{a}-\mathrm{b}) !}$.

We begin with the following result:

Theorem 1: Let $\varphi \in A$ be convex in U Then the Cesáro means $\sigma_{k}^{\mu}(z, \varphi), z \in U$ of order $\mu \geq 1$, of $\varphi^{\prime}(z)$ are zero-free on $\mathrm{U}$ for all $\mathrm{k}$. 
Proof: In view of Lemma 1, the analytic function $\varphi$ of the form (1) is convex in Uif

$$
\prod_{j=1}^{p} \Gamma\left(\beta_{j}+n_{j}\right) \geq 2 \underset{j=1}{q} \prod_{j=1} \Gamma\left(\alpha_{j}+n_{j}\right)+\prod_{j=1}^{p} \Gamma\left(\beta_{j}+n_{j}\right) \geq 3
$$

where, (2) holds. Let $\varphi(z):=\sum_{n=0}^{\infty}(n+1) z^{n+1}$ be defined such that:

$$
z \varphi^{\prime}(z)=\phi(z) * \varphi(z)=\sum_{n=0}^{\infty} \frac{(n+1)}{n !} \frac{\prod_{j=1}^{q} \Gamma\left(\alpha_{j}+n A_{j}\right)}{\prod_{j=1}^{p} \Gamma\left(\beta_{j}+n B_{j}\right)} z^{n+1}
$$

Then:

$$
\begin{aligned}
\sigma_{k}^{\alpha}\left(z, \varphi^{\prime}\right) & =\varphi^{\prime}(z)^{*} \sigma_{k}^{\mu}(z) \\
& =\frac{z \varphi^{\prime}(z) * z \sigma_{k}^{\mu}}{z} \\
& =\frac{\varphi(z)^{*} \varphi z^{*} z \sigma_{k}^{\mu}}{z} \\
& =\frac{\varphi(z)^{*} z\left(z \sigma_{k}^{\mu}\right)^{\prime}}{z}
\end{aligned}
$$

In view of Lemma 3, the relation (8) and the fact that $z \sigma_{k}^{\mu}$ is convex yield that there exists a function $\mathrm{g} \in \mathrm{S}^{*}$ and $\mathrm{p} \in \mathrm{P}$ with $\mathrm{p}(0)=1$ such that:

$$
\frac{\varphi(z) * z\left(z \sigma_{k}^{\mu}\right)^{\prime}}{z}=\frac{\varphi(z) * g p(z)}{z}=\frac{(\varphi(z) * g(z)) p_{1}(z)}{z} \neq 0
$$

We know that $\Re\left\{p_{1}(z)\right\}>0$ and that $\varphi(z) * g(z)=0$ if and only if $z=0$ Hence, $\sigma_{k}^{\mu}\left(z \varphi^{\prime}\right) \neq 0$ and the proof is complete.

Corollary 1: If $\mathrm{f}(\mathrm{U})$ is bounded convex domain, then the Cesáro means $\sigma_{\mathrm{k}}^{\mu}(\mathrm{z}), \mathrm{z} \in \mathrm{U}$ for the outer function $\varphi^{\prime}(\mathrm{z})$ are zero-free onU for all $\mathrm{k}$.

Proof: It comes from the fact that the derivatives of bounded convex functions are outer function ${ }^{[3]}$. The next result shows the upper and lower bound for $\sigma_{k}^{\mu}\left(z, \varphi^{\prime}\right)$.

Theorem 2: Let $\varphi \in A$ Assume that (2) and (10) hold. Then:

$$
\frac{1}{2}|\mathrm{z}|<\left|\sigma_{\mathrm{k}}^{\mu}\left(\mathrm{z}, \varphi^{\prime}\right)\right| \leq \frac{(\mathrm{k}+1)}{(\mathrm{k}-1) !} 1 \leq \mathrm{k}<\infty, \mathrm{z} \in \mathrm{U}, \mathrm{z} \neq 0
$$

Proof: Under the conditions of the theorem, we have that $\mathrm{f}$ is convex (Lemma 1.1), then in virtue of Theorem 1 , we obtain that $\sigma_{k}^{\mu}\left(z, \varphi^{\prime}\right) \neq 0$ thus $\sigma_{k}^{\mu}\left(z, \varphi^{\prime}\right)>0$ Now by applying Lemma 1.3 , on $\sigma_{k}^{\mu}\left(z, \varphi^{\prime}\right)$ and using the fact that $\mathfrak{R}\{\mathrm{z}\} \leq|\mathrm{z}|$ and since:

$$
\frac{\left(\begin{array}{l}
\mathrm{k}-\mathrm{n}+\mu \\
\mathrm{k}-\mathrm{n}
\end{array}\right)}{\left(\begin{array}{l}
\mathrm{k}+\mu \\
\mathrm{k}
\end{array}\right)}=\frac{\mathrm{k} !(\mathrm{k}-\mathrm{n}+\mu) !}{(\mathrm{k}-\mathrm{n}) !(\mathrm{k}+\mu) !} \leq 1
$$

for $\mu \geq 0$ and $n=0,1, \ldots, k$ yield:

$$
\frac{1}{2}<\Re\left\{\frac{\sigma_{\mathrm{k}}^{\mu}\left(\mathrm{z}, \varphi^{\prime}\right)}{\mathrm{z}}\right\} \leq \frac{\mid \sigma_{\mathrm{k}}^{\mu}\left(\mathrm{z}, \varphi^{\prime}\right)}{\mathrm{z}},|\mathrm{z}|>0 \text { and } \mathrm{z} \in \mathrm{U}
$$

For the other side, we pose that:

$$
\begin{aligned}
\left|\sigma_{k}^{\mu}\left(z, \varphi^{\prime}\right)\right| & =\left|\varphi^{\prime}(z) * \sigma_{k}^{\mu}(z)\right| \\
& =\left|\sum_{n=0}^{k} \frac{(n+1)}{n !} \frac{\left(\begin{array}{l}
k-n+\mu \\
k-n
\end{array}\right)}{\left(\begin{array}{l}
k+\mu \\
k
\end{array}\right)} \frac{\prod_{j=1}^{q} \Gamma\left(\alpha_{j}+n A_{j}\right)}{\prod_{j=1}^{p} \Gamma\left(\beta_{j}+n B_{j}\right)} z^{n}\right| \\
& \leq \sum_{n=0}^{k} \frac{(n+1)}{n !} \frac{\left(\begin{array}{l}
k-n+\mu \\
k-n
\end{array}\right)}{\left(\begin{array}{l}
k+\mu \\
k
\end{array}\right)} \frac{\prod_{j=1}^{\mathrm{q}} \Gamma\left(\alpha_{j}+n A_{j}\right)}{\prod_{j=1}^{p} \Gamma\left(\beta_{j}+n B_{j}\right)}\left|z^{n}\right| \\
& \leq \sum_{n=0}^{k} \frac{(n+1)}{n !} \frac{\left(\begin{array}{l}
k-n+\mu \\
k-n
\end{array}\right)}{\left(\begin{array}{l}
k+\mu \\
k
\end{array}\right)} \frac{\prod_{j=1}^{\mathrm{q}} \Gamma\left(\alpha_{j}+n A_{j}\right)}{\prod_{j=1}^{p} \Gamma\left(\beta_{j}+n B_{j}\right)} \\
& \leq \sum_{n=0}^{k} \frac{(n+1)}{n !} \leq \frac{(k+1)}{(k-1) !} k<\infty
\end{aligned}
$$

When, $\mathrm{n} \rightarrow \mathrm{k}$ Hence the proof. Finally, we give the following result:

Theorem 3: Let $\varphi \in A$ and let (2) holds. Then:

$$
\lim _{k \rightarrow \infty} \sigma_{k}^{\alpha}(z, \varphi)=\frac{z}{(1-z) \lambda^{\prime}} \lambda>1, z \in U
$$

Proof: From the assumption (2) and by (11) yield: 


$$
\begin{aligned}
& \left|\sigma_{k}^{\alpha}(z, \varphi)-\frac{z}{(1-z) \lambda}\right|=\left|\begin{array}{l}
\sum_{n=0}^{k} \frac{\left(\begin{array}{l}
k-n+\mu \\
k-n
\end{array}\right)}{\left(\begin{array}{l}
k+\mu \\
k
\end{array}\right)} \\
\frac{\prod_{j=1}^{q} \Gamma\left(\alpha_{j}+n A_{j}\right)}{\prod_{j=1}^{p} \Gamma\left(\beta_{j}+n B_{j}\right)} \frac{1}{n !} z^{n+1}-\sum_{n=0}^{\infty} \frac{(\lambda) n}{n !} z^{n+1}
\end{array}\right| \\
& =\frac{1}{n !}\left|\begin{array}{l}
\sum_{n=0}^{k} \frac{\left(\begin{array}{l}
k-n+\mu \\
k-n
\end{array}\right)}{\left(\begin{array}{l}
k+\mu \\
k
\end{array}\right)} \frac{\prod_{j=1}^{q} \Gamma\left(\alpha_{j}+n A_{j}\right)}{\prod_{j=1}^{p} \Gamma\left(\beta_{j}+n B_{j}\right)} \\
-(\lambda)_{n} \| z^{n+1}-\sum_{n=0}^{\infty} \frac{(\lambda)_{n}}{n !} z^{n+1}
\end{array}\right| \\
& \leq\left|\sum_{n=k+1}^{\infty} \frac{(\lambda)_{n}}{n !}-\sum_{n=1}^{k} \frac{(\lambda)_{n}}{n !}\right| \\
& =0 \text { ask } \rightarrow \infty
\end{aligned}
$$

\section{ACKNOWLEDGEMENT}

The work here was fully supported by eScience Fund: 04-01-02-SF0425, MOSTI, Malaysia.

\section{REFERENCES}

1. Barnard, R.W., J. Cima and K. Pearce, 1998. Cesáro sum approximation of outer functions. Ann. Uni. Marie Curie-Sklodowska Sect. A, 52: 1-7.
2. Cunningham, W., 1958. Introduction to Nonlinear Analysis. MeGraw-Hill, New York.

3. Duren, P.L., 1970. Theory of Hp Spaces. Academic Press.

4. Fox, C., 1928. The asymptotic expansion of the generalized hypergeometric function. J. London Math. Soc., 2: 389-400.

5. Ruscheweyh, S., 1982. Convolutions in Geometric Function Theory. Sem. Math. Sup., University of Montreal Press.

6. Ruscheweyh, S., 1992. Geometric Properties of Cesáro Means. Results Math., 22: 739-748.

7. Ruscheweyh, S. and L. Salinas, 1993. Subordination by Cesáro Means. Complex Var. Theor. Appl., 21: 279-285.

8. Splina, L.T., 2008. On certain applications of the hadamard product. App. Math. Comp., 199: 653-662.

9. Slater, L.J., 1966. Generalized Hypergeometric Functions. Cambridge University Press, London.

10. Wright, E.M., 1935. The asymptotic expansion of the generalized hypergeometric function. J. London Math. Soc., 10: 286-293.

11. Wright, E.M., 1940. The asymptotic expansion of the generalized hypergeometric function. J. London Math. Soc., 46: 389-408. 